\title{
Kualitas Lingkungan Air Sungai Sekitar Kegiatan Pertambangan Batubara
}

\author{
M. Fikri Hernandi \\ Forest Products \\ Technology Department, \\ Samarinda State of \\ Agriculture Polytechnic \\ fhernandi271170@gmail \\ .com
}

\author{
Wartomo \\ Forest Products \\ Technology Department, \\ Samarinda State of \\ Agriculture Polytechnic \\ wartomopoltanesa@gmail \\ .com
}

\author{
Abdul Rasyid Zarta* \\ Wood Engineering \\ Department, Samarinda \\ State of Agriculture \\ Polytechnic \\ zarta_poltanesa@yahoo \\ .com \\ *Corresponding author
}

\author{
Erna Rosita \\ Forest Management \\ Department, Samarinda \\ State of Agriculture \\ Polytechnic \\ Ernarositah7@gmail.com
}

\begin{abstract}
Abstrak - Kualitas air sungai di sekitar tambang batubara $100 \%$ atau 36 parameter air masih memenuhi baku mutu lingkungan air permukaan kelas II. Perlunya perhatian adanya beberapa parameter seperti tembaga, sulfida $\left(\mathrm{H}_{2} \mathrm{~S}\right)$, kesadahan, phosphat dengan tingkat kekritisan 6099\% yang mendekati batas baku mutu lingkungan. Sungai Separi Besar, Nilai indeks pencemaran Sungai Separi Besar diperoleh sebesar 0,771, Sungai Separi Anak sebesar 0,712 dan Sungai Tanjakan Kecil sebesar 0,746 dengan kategori status mutu air sungai masih menenuhi baku mutu (kondisi baik). Nilai Indeks Kualitas Air untuk Indeks Kualitas Lingkungan Hidup untuk sungai di sekitar kawasan tambang secara umum termasuk dalam kriteria sangat baik
\end{abstract}

Kata Kunci-air, batubara, pertambangan, kualitas lingkungan

\section{Pendahuluan}

Kalimantan Timur memiliki aset kekayaan sumberdaya alam (SDA) melimpah dan berskala besar, salah satunya adalah sumberdaya hutan tropis. Bidang kehutanan memiliki kontribusi besar dalam menopang pembangunan. Pemanfaatan dan pengelolaan SDA dikuasakan pada para investor melalui pemberian ijin konsesi dalam bentuk ijin usaha pemanfaatan, pengusahaan maupun penggunaan kawasan. Pemanfaatan dan pengembangan SDA pada kawasan pertambangan komoditas batubara mencapai 5,137 juta hektar dikelola perusahaan IUP seluas 4,131 juta hektar dan izin PKP2B seluas 1,006 juta hektar (Dinas ESDM Kalimantan Timur, 2019)

Konsekuensi logis dari eksplorasi dan eksploitasi SDA adalah munculnya dampak terhadap lingkungan baik lingkungan fisik, biologi maupun sosial. Penurunan lingkungan hidup telah tergambarkan dengan adanya peristiwa berupa pencemaran badan air dan udara, kontaminasi limbah bahan berbahaya dan beracun (B3), kerusakan ekosistem hutan hujan tropika, pemanasan bumi serta bencana lingkungan seperti banjir dan longsor, kekeringan, kebakaran hutan dan lahan yang cenderung terus meningkat. Laporan Dinas Lingkungan Hidup Provinsi Kalimantan Timur yang dikeluarkan pada
Januari 2019 mengemukakan beberapa isu lingkungan hidup dari aspek fisik antara lain yakni pencemaran air dan degradasi hutan.

Kerusakan lingkungan hidup yang ditimbulkan oleh operasi pertambangan merupakan kerusakan yang bersifat tidak dapat balik (irreversible damages). Subardja (2007) menambahkan dampak perubahan bentang alam dan tanah yang mengganggu ekosistem diatasnya, termasuk tata air aktibat aktivitas tambang terbuka (open pit) Pendapat ini juga diperkuat oleh Sayoga (2007), air asam tambang (acid mine drainage) sebagai hasil oksidasi oksigen di udara pada lingkungan berair dengan mineral sulfida merupakan permasalahan lingkungan dalam kaitannya dengan aktivitas pertambangan batubara

Isu utama degradasi sumberdaya alam dan lingkungan akibat kegiatan pertambangan khususnya batubara adalah rendahnya mutu air sungai. Indeks kuallitas air di Provinsi Kalimantan Timur tahun 20172020 : 57,79 (2017), 86,19 (2018), 62,01 (2019) menunjukan nilai yang fluktuatif dan belum menunjukkan perubahan yang signifikan.

Berbagai aktivitas penggunaan lahan di wilayah perairan sungai seperti aktivitas pertambangan batubara diperkirakan telah mempengaruhi kualitas air sungai. Menurut Priyambada et al. (2008) bahwa meningkatnya aktivitas domestik, pertanian dan industri akan mempengaruhi dan memberikan dampak terhadap kondisi kualitas air sungai terutama ditandai adanya perubahan tata guna lahan. Berdasarkan uraian tersebut di atas maka perlu dilakukan analisis kualitas dan status mutu air sungai sekitar kegiatan pertambangan batubara dalam upaya pengendalian pencemaran air. Tujuan penelitian ini adalah untuk menganalisis kualitas dan status mutu air sungai disekitar kegiatan pertambangan batubara sehingga diperoleh gambaran kawasan pertambangan batubara yang sudah mengalami perbaikan dan yang perlu dikelola

\section{Metodologi}

\section{A. Lokasi dan data penelitian}

Wilayah kegiatan pertambangan batubara PT XXX di Kabupaten Kutai Kartanegara Provinsi Kalimantan Timur. Lokasi sampling air sungai dilakukan di Sungai 
Separi Besar, Sungai Separi Anak dan Sungai Tanjakan Kecil

\section{B. Analisis data}

Pengolahan dan analisis data secara deskriptif melalui penilaian kualitas lingkungan air berdasarkan :

- Konsentrasi suatu parameter air dibandingkan dengan baku mutu air pada sumber air untuk sebuah peruntukkan tertentu : Peraturan Daerah Provinsi Kalimantan Timur Nomor 02 Tahun 2011 Tentang Pengelolaan Kualitas Air Dan Pengendalian Pencemaran Air.

- Penentuan status mutu air dengan metoda indeks pencemaran (Pollution Index) dan indeks kualitas air (IKA) : Keputusan Menteri Negara Lingkungan Hidup Nomor 115 Tahun 2003 tentang Pedoman Penentuan Status Mutu Air

- Dalam penelitian ini menggunakan metode indeks pencemaran $(\mathrm{PIj})$. Sebagai metode berbasis indeks, metode IP dibangun berdasarkan dua indeks kualitas. Yang pertama adalah indeks rata-rata (IR). Indeks ini menunjukkan tingkat pencemaran rata-rata dari seluruh parameter dalam satu kali pengamatan. Yang kedua adalah indeks maksimum (IM). Indeks ini menunjukkan satu jenis parameter yang dominan menyebabkan penurunan kualitas air pada satu kali pengamatan. Kategori penilaian kualitas air berdasarkan nilai IP adalah sebagai berikut (KepMen.LH 115/2003): Memenuhi baku mutu : IP $\leq 1$; Tercemar ringan : $1<\mathrm{IP} \leq 5$; Tercemar sedang : $5<$ IP $\leq 10$; Tercemar berat : IP $>10$

- $\quad$ Perhitungan IKA dilakukan berdasarkan nilai dari Pij sebagai berikut: IKA $=100$, untuk $\mathrm{Pij} \leq 1$; IKA $=80$, untuk $1<\mathrm{Pij} \leq 4,67$; IKA $=60$, untuk 4,67 $<\mathrm{Pij} \leq$ 6,$32 ; \mathrm{IKA}=40$, untuk $6,32<\mathrm{Pij} \leq 6,88 ; \mathrm{IKA}=20$, untuk Pij > 6,88

\section{HASIL DAN PEMBAHASAN}

Wilayah studi memiliki beberapa pola aliran sungai yang sangat dipengaruhi oleh morfologi, litologi, dan struktur geologi. Secara umum pola aliran daerah berbentuk Dendritik dimana pola aliran ini berbentuk seperti cabang pohon dan berada didaerah datar dengan struktur batuan homogen dan juga berbentuk Rectangular dimana pola aliran sungai dikendalikan oleh struktur geologi, seperti struktur kekar (rekahan) dan sesar (patahan). Daerah Aliran Sungai pada daerah penelitian memiliki dua sungai besar yang langsung mengarah ke sungai Mahakam yaitu sungai Separi Besar dan sungai Separi Kecil yang berada diwilayah kecamatan Tenggarong Seberang. Berdasarkan peta hidrologi, lokasi pertambangan termasuk dalam 2 sub daerah aliran sungai yakn SUBDAS Separi Besar seluas 954,07 Ha (34,72\%) dan SUBDAS Separi Kecil seluas 1.793,93 (65.28\%).

Gambaran kondisi kualitas air sungai pada tiap-tiap parameter yang diukur mencerminkan karakteristik kualitas air sungai terutama untuk melihat kesesuaian terhadap peruntukkannya. Peruntukan air sungai akan menjadi berbeda-beda ditentukan oleh kualitas air berdasarkan kandungan zat-zat yang terdapat dalam air baik pada kondisi tersuspensi maupun terlarut. Keberadaan zat-zat tersebut pada kadar tertentu dikatakan sebagai zat pencemar jika besarannya telah merubah kualitas air sesuai peruntukkannya. Kualitas air sungai merupakan salah satu gambaran daya dukung lingkungan khususnya air permukaan untuk menunjang komponen lingkungan termasuk di dalamnya manusia. Untuk mengetahui kualitas air tersebut, maka diperlukan adanya pengukuran terhadap parameter fisik, kimia dan biologi. Hasil pengukuran kualitas air sungai di wilayah studi dibandingkan kualitasnya berdasarkan Peraturan Daerah Propinsi Kalimantan Timur Nomor : 02 Tahun 2011 dan khusus parameter Fecal Coliform dan Total Coliform menggunakan Peraturan Pemerintah Nomor : 82 Tahun 2001 tentang Pengelolaan Kualitas Air dan Pengendalian Pencemaran Air. Peruntukan sungai-sungai yang termasuk dalam wilayah studi saat ini belum jelas apakah masuk dalam Mutu Air Kelas I, II, III atau IV, karena belum ditetapkan oleh pemerintah melalui peraturan perundang-undangan sesuai dengan Pasal 9, ayat 1 huruf a, b dan c, Peraturan pemerintah Nomor : 82 Tahun 2001. Namun sesuai dengan Peraturan Pemerintah Nomor : 82 Tahun 2001 khususnya pada Pasal 55, bahwa untuk badan air yang belum ditetapkan peruntukannya, berlaku kriteria Baku Mutu Air Kelas II. 
Tabel 1. Hasil Analisis Kualitas Air Permukaan

\begin{tabular}{|c|c|c|c|c|c|c|c|}
\hline \multirow[b]{2}{*}{ No. } & \multirow[b]{2}{*}{ Parameter } & \multirow[b]{2}{*}{ Satuan } & \multirow[b]{2}{*}{$\begin{array}{l}\text { Baku } \\
\text { Mutu }\end{array}$} & \multicolumn{3}{|c|}{ HASIL } & \multirow[t]{2}{*}{ METODE } \\
\hline & & & & $\begin{array}{c}\text { Sungai } \\
\text { Separi } \\
\text { Anak }\end{array}$ & $\begin{array}{c}\text { Sungai } \\
\text { Tanjakan } \\
\text { Kecil }\end{array}$ & $\begin{array}{l}\text { Sungai } \\
\text { Separi } \\
\text { Besar }\end{array}$ & \\
\hline A. & \multicolumn{7}{|l|}{ FISIKA } \\
\hline 1. & \multirow{2}{*}{$\begin{array}{c}\text { Suhu } \\
\text { Warna }\end{array}$} & ${ }^{\circ} \mathrm{C}$ & Devisa 3 & 30,2 & 30 & 30 & SNI 06.6989.23-2005 \\
\hline 2. & & $\mathrm{PtCo}$ & 180 & 8,12 & 8,11 & 8,28 & SNI 06.6989.24-2005 \\
\hline 3. & $\begin{array}{ll}\begin{array}{l}\text { Residu } \\
\text { (TSS) }\end{array} & \text { Tersuspensi } \\
\end{array}$ & $\mathrm{mg} / \mathrm{L}$ & 50 & 24 & 28 & 32 & SNI 06.6989.3-2004 \\
\hline 4. & Residu Terlarut (TDS) & $\mathrm{mg} / \mathrm{L}$ & 1000 & 288 & 292 & 298 & SNI 06.6989.27-2005 \\
\hline B. & \multicolumn{3}{|c|}{ KIMIA ANORGANIK } & & & & \\
\hline 5. & $\mathrm{pH}$ & - & $6-9$ & 7,08 & 7,32 & 6,78 & SNI 06.6989.11-2005 \\
\hline 6, & Besi & $\mathrm{mg} / \mathrm{L}$ & $(-)$ & 0,128 & 0,118 & 0,222 & SNI 6989.4-2009 \\
\hline 7. & Mangan & $\mathrm{mg} / \mathrm{L}$ & $(-)$ & 0,008 & 0,012 & 0,018 & SNI 6989.5-2009 \\
\hline 8. & Barium & $\mathrm{mg} / \mathrm{L}$ & $(-)$ & $<0,001$ & $<0,005$ & $<0,005$ & SNI 06.6989.39-2005 \\
\hline 9. & Tembaga & $\mathrm{mg} / \mathrm{L}$ & 0.02 & 0,012 & 0,018 & 0,019 & SNI 6989.6-2009 \\
\hline 10. & Seng & $\mathrm{mg} / \mathrm{L}$ & 0.05 & 0,038 & 0,032 & 0,043 & SNI 6989.7-2009 \\
\hline 11. & Khrom (VI) & $\mathrm{mg} / \mathrm{L}$ & 0.05 & TTD & TTD & TTD & SNI 06.6989.17-2004 \\
\hline 12. & Kadmium & $\mathrm{mg} / \mathrm{L}$ & 0.01 & TTD & TTD & TTD & SNI 06.6989.16-2009 \\
\hline 13. & Mercury (Hg) & $\mathrm{mg} / \mathrm{L}$ & 0,002 & TTD & TTD & TTD & SNI 6989.78-2011 \\
\hline 14. & Timbal & $\mathrm{mg} / \mathrm{L}$ & 0.03 & TTD & TTD & TTD & SNI 6989.8-2009 \\
\hline 15. & Arsen & $\mathrm{mg} / \mathrm{L}$ & 1 & 0,007 & 0,003 & 0,004 & SNI 06.6989.54-2005 \\
\hline 16. & Selenium & $\mathrm{mg} / \mathrm{L}$ & 0.05 & $<0,001$ & $<0,005$ & $<0,005$ & SNI 06.2475-1991 \\
\hline 17. & Kobalt & $\mathrm{mg} / \mathrm{L}$ & 0.2 & $<0,002$ & $<0,005$ & $<0,005$ & SNI 06.2473-1991 \\
\hline 18. & Sianida & $\mathrm{mg} / \mathrm{L}$ & 0.02 & $<0,002$ & $<0,005$ & $<0,005$ & SNI 19.1664-1989 \\
\hline 19. & Sulfida $\left(\mathrm{H}_{2} \mathrm{~S}\right)$ & $\mathrm{mg} / \mathrm{L}$ & 0,002 & 0,0018 & 0,0019 & 0,0019 & SNI 6989.75-2009 \\
\hline 20. & Fluorida & $\mathrm{mg} / \mathrm{L}$ & 1.5 & 0,2122 & 0,2733 & 0,3788 & SNI 06.6989.29-2005 \\
\hline 21. & Klorin bebas & $\mathrm{mg} / \mathrm{L}$ & 0.03 & 0,02 & 0,02 & 0,02 & SNI 06.4824-1998 \\
\hline 22. & Kesadahan sbg $\mathrm{CaCO}_{3}$ & $\mathrm{mg} / \mathrm{L}$ & 50 & 38 & 42 & 48 & SNI 7644-2010 \\
\hline 23. & Khlorida & $\mathrm{mg} / \mathrm{L}$ & 600 & 0,1282 & 0,1887 & 0,1988 & SNI 6989.19-2009 \\
\hline 24. & Sulfat & $\mathrm{mg} / \mathrm{L}$ & $(-)$ & 10,2122 & 12,1212 & 18,1233 & SNI 6989.20-2009 \\
\hline 25. & DO & $\mathrm{mg} / \mathrm{L}$ & 4 & 4,92 & 4,98 & 5,12 & SNI $06.69889 .14-2004$ \\
\hline 26. & Phosphat & $\mathrm{mg} / \mathrm{L}$ & 0.2 & 0,1877 & 0,1954 & 0,1982 & SNI 06.6989.31-2005 \\
\hline 27. & Boron & $\mathrm{mg} / \mathrm{L}$ & 1 & $<0,001$ & $<0,005$ & $<0,005$ & SNI 06.2481-1991 \\
\hline 28. & Nitrat $\left(\mathrm{NO}_{3}-\mathrm{N}\right)$ & $\mathrm{mg} / \mathrm{L}$ & 10 & 2,1288 & 2,2344 & 2,8872 & SNI 6989.74-2009 \\
\hline 29. & Nitrit $\mathrm{s}\left(\mathrm{NO}_{2}-\mathrm{N}\right)$ & $\mathrm{mg} / \mathrm{L}$ & 0.06 & 0,0122 & 0,0344 & 0,0466 & SNI 06.6989.9-2004 \\
\hline 30. & BOD-5 & $\mathrm{mg} / \mathrm{L}$ & 3 & 1,12 & 1,14 & 1,19 & APHA, $5210-\mathrm{B}, 22^{\mathrm{ND}}$ th. 2012 \\
\hline 31. & COD & $\mathrm{mg} / \mathrm{L}$ & 25 & 8,7228 & 8,9828 & 9,2221 & SNI 06.6989.73-2009 \\
\hline 32. & Amoniak $\left(\mathrm{NH}_{3}-\mathrm{N}\right)$ & $\mathrm{mg} / \mathrm{L}$ & $(-)$ & 0,2128 & 0,2872 & 0,3455 & SNI 06.6989.30-2005 \\
\hline C. & MICROBIOLOGI & & & & & & \\
\hline 33. & Fecal Coliform & $\mathrm{Jml} / 100 \mathrm{ml}$ & - & 120 & 132 & 135 & Most Probable Number (MPN) \\
\hline 34. & Fecal Coliform & $\mathrm{Jml} / 100 \mathrm{ml}$ & 1000 & 32 & 28 & 42 & Most Probable Number (MPN) \\
\hline D. & KIMIA ORGANIK & & & & & & \\
\hline 35. & Detergen sbg MBAS & $\mathrm{mg} / \mathrm{L}$ & 200 & 15,8122 & 21,9122 & 24,1218 & SNI 06.6989.51-2005 \\
\hline 36. & Minyak dan Lemak & $\mathrm{mg} / \mathrm{L}$ & 1000 & 12,2122 & 15,1244 & 18,4522 & SNI 06.6989.10-2011 \\
\hline
\end{tabular}

Berdasarkan hasil analisis laboratorium menunjukkan $100 \%$ atau 36 parameter air masih memenuhi baku mutu lingkungan air permukaan kelas II. Namun demikian perlunya perhatian adanya beberapa parameter seperti tembaga, sulfida $\left(\mathrm{H}_{2} \mathrm{~S}\right)$, kesadahan, phosphat yang mendekati batas baku mutu lingkungan dengan tingkat kekritisan parameter air berkisar antara $60-99 \%$. Tinggi kekritisan parameter mendekati batas ambang mutu air menunjukkan aktivitas penggunan lahan sekitar sungai tersebut berkontribusi terhadap peningkatan parameter air tersebut. Tingginya konsentrasi sulfida $\left(\mathrm{H}_{2} \mathrm{~S}\right)$ pada air sungai tersebut menunjukkan bahwa adanya proses degradasi bahan organik secara anaerob. Purnomo et al., 2013 mengemukan hidrogen Sulfida $\left(\mathrm{H}_{2} \mathrm{~S}\right)$ merupakan gas yang dihasilkan dari proses penguraian senyawa belerang dari bahan organik oleh bakteri anaerob akibat air sungai yang tidak mengandung oksigen terlarut.
Proses anaerob terjadi di perairan yang airnya tidak bersirkulasi dan tidak mempunyai kontak langsung dengan udara sehingga mengurangi kemampuan air untuk melarutkan oksigen sehingga penguraian bahan organik akan dilakukan oleh mikroorganisme anaerob yang mengeluarkan gas asam sulfida $\left(\mathrm{H}_{2} \mathrm{~S}\right)$ dan gas metana. Konsentrasi fosfat yang tinggi ini mungkin disebabkan tingginya difusi fosfat dari sedimen. Sedimen merupakan tempat penyimpanan utama fosfor, umumnya dalam bentuk partikulat yang berikatan dengan senyawa hidroksida dan oksida besi. Senyawa fosfor yang terikat di sedimen dapat mengalami dekomposisi dengan bantuan bakteri maupun melalui proses abiotik menghasilkan senyawa fosfat terlarut yang dapat mengalami difusi kembali ke kolom air (Paytan and McLaughlin, 2007). Sumber utama penyumbang fosfat adalah limbah domestik masyarakat. Menurut WHO \& 
European Commision (2002), pengkayaan fosfor terutama berasal dari limbah rumah tangga dan industri, termasuk detergen berbahan dasar fosfor. Menurut Abidjulu, 2008, kapur (CaCO) dapat larut dalam air akibat adanya $\mathrm{CO}$ yang membentuk mineral-mineral karbonat yang larut dalam air. Peningkatan tingkat kesadahan air diduga juga dapat disebabkan oleh meningkatnyanya ion-ion $\mathrm{Ca}^{2+}$ dan $\mathrm{Mg}^{3+}$ dalam air. Peningkatan ion-ion $\mathrm{Ca}^{2+}$ dan $\mathrm{Mg}^{3+}$ dalam air diduga terjadi akibat perubahan ion-ion tersebut menjadi padatan yang tidak larut dalam air dan mengendap di dasar sungai sebagai padatan $\mathrm{CaCO}_{3}$ dan $\mathrm{MgCO}_{3}$. Masuknya $\mathrm{Ca}(\mathrm{OH})_{2}$ ke perairan sungai tersebut dapat terjadi secara alami dari limbah yang berasal dari aktivitas domestik (Ruliasih, 2011). Peningkatan logam berat tenbaga akibat proses pelapukan batuan, menurut Colbourne et al. (1975) mengemukakan peningkatan konsentrasi logam tembaga $\mathrm{Cu}$ seiring dengan pengkayaan elemen tersebut dari proses pelapukan batuan.

\section{Status Mutu Air dengan Metoda Indeks Pencemaran}

Untuk menentukan tingkat pencemaran relatif terhadap parameter kualitas air yang diizinkan digunakan penentuan status mutu air dengan metoda indeks pencemaran. Status mutu air menunjukkan tingkat kondisi mutu air sumber air dalam kondisi tercemar apabila tidak dapat digunakan sesuai dengan peruntukaannya secara normal atau kondisi baik dengan membandingkan dengan baku mutu yang telah ditetapkan. Bila nilai IP lebih kecil dari 1,0, maka sampel air tersebut memenuhi baku mutu termaksud, sedangkan bila lebih besar dari 1,0, sampel dinyatakan tidak memenuhi baku mutu.

Pengelolaan kualitas air atas dasar indeks pencemaran ini dapat memberi masukan pada pengambil keputusan agar dapat menilai kualitas badan air untuk peruntukan serta melakukan tindakan untuk memperbaiki kualitas jika terjadi penurunan kualitas akibat senyawa pencemar (Kepmen LH No.115 Tahun 2003). Hasil analisis nilai indeks pencemaran disajikan pada Tabel 2 dan Gambar 2.

Tabel 2. Hasil Perhitungan Status Mutu Air dengan Metoda Indeks Pencemaran

\begin{tabular}{|c|c|c|}
\hline $\begin{array}{c}\text { Sampling } \\
\text { Sungai }\end{array}$ & $\begin{array}{c}\text { Nilai Indeks } \\
\text { Pencemaran }\end{array}$ & Status Mutu Air \\
\hline $\begin{array}{c}\text { Sungai Separi } \\
\text { Besar }\end{array}$ & 0,771 & $\begin{array}{c}\text { memenuhi baku } \\
\text { mutu }(\text { good })\end{array}$ \\
\hline $\begin{array}{c}\text { Sungai Separi } \\
\text { Anak }\end{array}$ & 0,712 & $\begin{array}{c}\text { memenuhi baku } \\
\text { mutu }(\text { good })\end{array}$ \\
\hline $\begin{array}{c}\text { Sungai } \\
\text { Tanjakan Kecil }\end{array}$ & 0,746 & $\begin{array}{c}\text { memenuhi baku } \\
\text { mutu }(\text { good })\end{array}$ \\
\hline
\end{tabular}

Dari hasil perhitungan indeks pencemaran tersebut di atas menunjukkan bahwa kualitas air sungai sekitar kegiatan pertambangan masih baik. Hasil analisis Indeks Pencemaran $(P I j)$, menunjukan bahwa ketiga sungai di sekitar tambang memenuhi baku mutu (good). Status mutu air sungai kategori memenuhi baku mutu mengindikasikan bahwa kondisi kualitas air sungai atau parameter yang masih memenuhi baku mutu lingkungan.
Hal ini menunjukan adanya akivitas penggunaan lahan dan masyarakat di sekitarnya kondisi kualitas air sungai masih dalam baik atau memenuhi baku mutu lingkungan

\section{Indeks Kualitas Air}

Nilai Indek Kualitas Air dan Indeks Kualitas Lingkungan Hidup memberikan gambaran atau indikasi awal yang memberikan kesimpulan cepat dari suatu kondisi lingkungan hidup pada lingkup dan periode tertentu yakni memberikan Informasi tentang kondisi lingkungan sebagai bahan evaluasi kebijakan pembangunan yang berkelanjutan dan berwawasan lingkungan. Hasil penghitungan nilai indeks kualitas air disajikan selengkapnya pada Tabel 3.

Tabel 3. Hasil Penghitungan Nilai Indeks Kualitas Air dan Indeks Kualitas Lingkungan Hidup

\begin{tabular}{|c|c|c|}
\hline Lokasi & $\begin{array}{c}\text { Indeks } \\
\text { Kualitas Air } \\
(\%)\end{array}$ & $\begin{array}{c}\text { Kriteria Indeks } \\
\text { Kualitas } \\
\text { Lingkungan Hidup }\end{array}$ \\
\hline $\begin{array}{c}\text { Sungai Separi } \\
\text { Besar }\end{array}$ & 100 & Sangat Baik \\
\hline $\begin{array}{c}\text { Sungai Separi } \\
\text { Anak }\end{array}$ & 100 & Sangat Baik \\
\hline $\begin{array}{c}\text { Sungai } \\
\text { Tanjakan } \\
\text { Kecil }\end{array}$ & 100 & Sangat Baik \\
\hline
\end{tabular}

Nilai Indeks Kualitas Air untuk Indeks Kualitas Lingkungan Hidup untuk sungai di sekitar kawasan tambang secara umum termasuk dalam kriteria sangat baik. Hal ini menunjukkan pengelolaan lingkungan di kawasan penambangan batubara dalam upaya perbaikan kualitas lingkungan hidup mampu menekan penurunan pemanfaatan sumber daya lingkungan.

Untuk kinerja pengelolaan kualitas air perlu ditingkatkan agar kualitas air tidak melampaui baku mutu yang telah dipersyaratkan. Kinerja pengelolaan yang telah dilakukan PT XXX untuk menjaga kualitas air diantaranya adalah optimalisasi pengolahan air limbah di sedimen pond terutama yang paling dekat dengan saluran umum, dan menindak lanjutinya dengan pemberian $\mathrm{Al}_{2} \mathrm{SO}_{4}$ (tawas) dan kapur $\left(\mathrm{CaCO}_{3}\right)$ sebelum air dibuang keperairan umum. Penggunaan kapur berlebih atau tidak sesuai dosis akan bereaksi dengan logam-logam atau kation-kation yang bervalensi dua seperti Fe, Sr, Mn, Ca dan $\mathrm{Mg}$, sehingga menyebabkan meningkatnya kesadahan total di air sungai. Tingginya klorin bebas dan belerang selain meningkat bahan organik di sungai, juga perlu memperhatikan dosis penggunaan pupuk kimia dan pestisida dalam kegiatan perbaikan tanah dan tanaman. Prioritas kebijakan yang perlu dilakukan untuk mencegah terjadinya pencemaran air dan penurunan kualitas air sehingga air sungai agar dapat dimanfaatkan sesuai dengan peruntukannya secara berkelanjutan sebagai berikut: inventarisasi dan identifikasi sumber pencemar air, pengelolaan limbah, menetapkan daya tampung beban pencemaran, pengawasan terhadap pembuangan air limbah, pemantauan kualitas air sungai serta partisipasi dari masyarakat dalam upaya pengendalian pencemaran air. 


\section{KESIMPULAN}

Kualitas air sungai di sekitar tambang batubara $100 \%$ atau 36 parameter air masih memenuhi baku mutu lingkungan air permukaan kelas II. berdasarkan Peraturan Daerah Provinsi Kalimantan Timur Nomor 02 Tahun 2011 Tentang Pengelolaan Kualitas Air Dan Pengendalian Pencemaran Air untuk peruntukkan kelas II. Namun demikian perlunya perhatian adanya beberapa parameter seperti tembaga, sulfida $\left(\mathrm{H}_{2} \mathrm{~S}\right)$, kesadahan, phosphat dengan tingkat kekritisan 60-99\% yang mendekati batas baku mutu lingkungan

Kualitas air sungai sekitar tambang batuabara berdasarkan analisis mutu air sungai dengan metode indeks pencemaran menunjukkan Sungai Separi Besar, Separi Anak dan Tanjakan Kecil dikatagorikan sebagai sungai dengan status mutu masih menenuhi baku mutu (kondisi baik)

Nilai Indeks Kualitas Air untuk Indeks Kualitas Lingkungan Hidup untuk sungai di sekitar kawasan tambang secara umum termasuk dalam kriteria sangat baik.

Pengelolaan dan pemantauan air sungai perlu dilaksanakan secara kontinyu dan berkala untuk mendapatkan informasi kualitas air sungai yang digunakan mendukung upaya pengelolaan kualitas air sungai di Provinsi Kalimantan Timur. Kualitas air sungai di wilayah tambang perlu dipertahankan dengan melakukan pengendalian pencemaran air melalui penerapan aturan yang ketat dan konsisten; lokalisasi terhadap sumber pencemar; penghijauan atau penanaman pohon; melakukan tata kelola kawasan sesuai peruntukkannya; dan mempertahankan serta mengembangkan kawasan hijau di wilayah tambang, dll.

\section{DAFTAR PUSTAKA}

2001. Peraturan Pemerintah Republik Indonesia No. 82 Tahun 2001 tentang Pengelolaan Kualitas Air dan Pengendalian Pencemaran Air.

2013. Keputusan Menteri Negara Lingkungan Hidup Nomor 115 Tahun 2003 tentang Pedoman Penentuan Status Mutu Air

2011. Peraturan Daerah Provinsi Kalimantan Timur Nomor 02 Tahun 2011 Tentang Pengelolaan Kualitas Air Dan Pengendalian Pencemaran Air

Abidjulu J., 2008. Analisis Kualitas Air Sungai Tanoyan Di Kota Kotamobagu Provinsi Sulawesi Utara. Chem. Prog. Vol. 1, No. 2. November 2008

Agatha Sih Piranti, Diana Rus Rahayu, Gentur Waluyo. 2018. Evaluasi Status Mutu Air Danau Rawapening. Jurnal Pengelolaan Sumberdaya Alam dan Lingkungan Vol. 8 No. 2 (Agustus 2018): 151-160
Colbourne P, Alloway BJ, Flrornton I (1975) Arsenic and Heavy Metal Soils associated with regional Geochemicals anaomalies in Southwest England, Sci Total Environ 4:3 59-363 pp

Dinas Pertambangan dan Energi Provinsi Kalimantan Timur. 2019. IUP Kalimantan Timur. http://pertambangan.kaltimprov.go.id/iup kalimantan timur

Djoharam, V., Etty R., Mohamad Y.. 2018. Analisis Kualitas Air Dan Daya Tampung Beban Pencemaran Sungai Pesanggrahan Di Wilayah Provinsi Dki Jakarta. Jurnal Pengelolaan Sumberdaya Alam dan Lingkungan Vol. 8 No. 1 (April 2018): 127-133

Fachlevi T.A., Eka I.K.P , Sahat M.H. Simanjuntak. 2015. Dampak Dan Evaluasi Kebijakan Pertambangan Batubara Di Kecamatan Mereubo. Risalah Kebijakan Pertanian dan Lingkungan. Vol. 2 No. 2, Agustus 2015: 171180. ISSN : 2355-6226. E-ISSN : 2477-0299

Fatmawati, Budiman, Letizia D. Dampak Lingkungan Galian Tambang Batubara PT. Kaltim Prima Coal Bagi Kesehatan Masyarakat Di Kecamatan Sangatta Utara Kabupaten Kutai Timur

Gatto, N.M., Henderson, V.W., Hodis, H.N., St. John, S.A., Lurmann, F., Chen, JC., dan Mack, W.J. 2014. Components Of Air Pollution And Cognitive Function In Middle-Aged And Older Adults In Los Angeles. Neurotocxycology. 40:17.

Jesica O Patty, Ratna Siahaan, Pience V Maabuat. 2018. Kehadiran Logam-Logam Berat $(\mathrm{Pb}, \mathrm{Cd}, \mathrm{Cu}$, Zn) Pada Air dan Sedimen Sungai Lowatag, Minahasa Tenggara - Sulawesi Utara. JURNAL BIOSLOGOS, FEBRUARI 2018, VOL. 8 NOMOR 1

Mahyudin, Soemarno, Tri B.P. 2015 Analisis Kualitas Air Dan Strategi Pengendalian Pencemaran Air Sungai Metro di Kota Kepanjen Kabupaten Malang. J-PAL, Vol. 6, No. 2, 2015.

Marganingrum, D dan Rhazista N.. 2010. Pencemaran Air Dan Tanah Di Kawasan Pertambangan Batubara Di PT. Berau Coal, Kalimantan Timur. Riset Geologi dan Pertambangan Vol. 20 No. 1 (2010), 11-20

Paytan, A.\& K. McLaughlin 2007. The Oceanic Phosphoru s Cycle. Chem. Rev., 107(2): 563-576

Piranti, A.S., Diana R.R., Gentur W. 2018. Evaluasi Status Mutu Air Danau Rawapening. Jurnal Pengelolaan Sumberdaya Alam dan Lingkungan Vol. 8 No. 2 (Agustus 2018): 151-160

Priyambada. I.B., w. Oktiawan, and R. P. E. Suprapto, "Analisa Pengaruh Perbedaan Fungsi Tata Guna 
Lahan Terhadap Beban Cemaran Bod Sungai (Studi Kasus: Sungai Serayu - Jawa Tengah)," Jurnal Presipitasi : Media Komunikasi dan Pengembangan Teknik Lingkungan, vol. 5 , no. 2, pp. 55-62, Sep. 2008

Purnomo, P.W., M. Nitisupardjo, Y. Purwandari, 2013. Hubungan Antara Total Bakteri Dengan Bahan Organik, NO3 dan H2S Pada Lokasi Sekitar Eceng Gondok dan Perairan Terbuka Di Rawa Pening. Journal of Management of Aquatic Resources. 2(3), pp. 74 \pm 84 .

Ruliasih. 2011. Penghilangan Kesadahan dalam Air Minum.

http://www.kelair.bppt.go.id/publikasi/BukuAir Minum/BAB9SADAH/pdf

Sayoga, R. G. 2007. Pengelolaan Air Tambang: Aspek Penting dalam Pertambangan yang Berwawasan Lingkungan. Pidato Ilmiah, majelis Guru Besar ITB. Jurusan Teknik Pertambngan ITB.

Simon I. Patty, Hairati Arfah, Malik S. Abdul. 2015. Zat Hara (Fosfat, Nitrat), Oksigen Terlarut Dan Ph Kaitannya Dengan Kesuburan Di Perairan Jikumerasa, Pulau Buru. Jurnal Pesisir dan Laut Tropis. Volume 1 Nomor 1 Tahun 2015

Subardja, A et al. 2007. Pemulihan Kualitas Lingkungan Penambangan Batubara: Karakterisaasi dan Pengendalian air asam Tambang di Berau. Laporan Teknis, Proyek DIPA Puslit Geoteknologi - LIPI TA 2007.

Wardana, A., dan Wisnu. 2001. Dampak Pencemaran Lingkungan. Yogyakarta

World Health Organization and European Commission. 2002. Eutrophication and Health. Edited by K. Pond. Luxembourg: Office for official Publication of the European communities. p 28. 